\title{
Das ruas para os Jogos Olímpicos? Dinâmicas em torno da prática do skate
}

\section{Maurício Bacic Olic INTRODUÇÃ O: PENSAR 0 SKATE NA ATUALIDADE (UNESP)}

Dados de 2010 publicados pelo Instituto Datafolha mostram que atualmente existem cerca de três milhões e oitocentos mil skatistas no Brasil. Este número é superior aos dois milhões e meio registrado em pesquisa realizada dez anos antes. A quantidade de skatistas no Brasil só é inferior à encontrada nos Estados Unidos, país onde o skate foi inventado e, até os dias de hoje, referência no desenvolvimento de produtos, estilos e eventos envolvendo sua prática. Neste país, entre os anos de 1998 e 2007, o número de skatistas saltou de cinco milhões e oitocentos mil para dez milhões e cem mil (Brandão; Honorato 2012: 13). No caso da cidade de São Paulo, segundo pesquisa realizada pelo Centro de Estudos de Cultura Contemporânea, o skate no início do século XXI passou a ocupar a segunda posição entre os esportes mais praticados pelos jovens que frequentam escolas públicas, só perdendo em número de adeptos para o futebol (Dimenstein 2002).

Os números apresentados acima evidenciam o crescimento do skate na cena urbana e juvenil contemporânea. Neste sentido, o presente artigo tem como objetivo acompanhar as transformações de sua prática nas últimas décadas, especialmente no Brasil, a partir do diálogo envolvendo aproximações e conflitos com a cidade e seus agentes. No segundo momento será apresentada a discussão existente no meio do skate sobre as vantagens e desvantagens do skate se transformar em uma modalidade olímpica. A razão de realizar estes dois recortes é perceber, em primeiro lugar, como foi sendo construída uma essência skatista resultante das interações promovidas pelos skatistas no meio urbano. Na medida em que o skate passou a construir para si um estilo de vida singular na cidade, sua presença no espaço público acabou produzindo relações de sedução e conflito com esferas cada vez mais heterogêneas da vida social. Ou seja, com o tempo a prática do skate passou a ganhar uma maior visibilidade, de modo a atrair a atenção, sobretudo, do 
mercado relacionado a indústria cultural e, no caso brasileiro, o skate encontrou no diálogo com o poder público a possibilidade de expandir sua "estrutura esportiva" por meio de políticas voltadas a construção de pistas públicas de skate, assim como ao patrocínio e promoção de competições.

No segundo instante, a discussão em torno da relação entre skate e Jogos Olímpicos será entendida como um desdobramento processual resultante da maior capilarização e visibilidade do skate na sociedade. Para isso, o conceito de "esportificação" desenvolvido por Norbert Elias e Eric Dunning (1992) será uma importante ferramenta teórica para pensar a dinâmica do skate enquanto uma prática que constantemente negocia sua relação com a dimensão esportiva, ora negando sua filiação a este campo, ora incorporando sua lógica de organização. Situação esta que acabou colocando o skate nos interstícios dos padrões que determinam e delimitam as práticas esportivas. Contudo, como chamam a atenção Elias e Dunning, pelo fato de as práticas esportivas e de lazer serem um tema ainda pouco explorado nas teorias sociais, e geralmente serem associadas a uma espécie de subcategoria da dimensão do trabalho, é necessário desenvolver um novo olhar sobre estas atividades. Neste sentido, os autores encaram o esporte em sua interdependência com a sociedade, ou seja, o esporte é pensado como uma manifestação lúdica desenvolvida na sociedade urbana industrial que contribui para o seu processo civilizador. A emergência dos desportos modernos, portanto, foi um instrumento fundamental para o processo de parlamentarização dos conflitos e de pacificação da esfera pública. Assim, o processo de "esportificação" envolve dinâmicas pelo qual as atividades esportivas passam a ser normatizadas por regras que exercem uma força sobre os indivíduos de autocontrole com base em valores civilizados relacionados a igualdade, justiça e democracia.

No presente artigo, este conceito será utilizado para entender a genealogia do skate. Desde seu surgimento em um período de profundas transformações sociais, especialmente no que diz respeito a dimensão comportamental e a ressignificação do "ser jovem" no final do século XX, passando pela forma como os skatistas passaram a construir um estilo de vida singular no meio urbano, até os dias de hoje em que o skate vem ganhando grande visibilidade no espaço público e atraindo interesses da indústria cultural ao mesmo tempo em que busca manter sua essência. Logo, durante todo o texto o conceito de "esportificação" será trabalhado em constante diálogo com o termo nativo essência skatista. Esta categoria é a forma como seus praticantes expressam a singularidade do estilo de vida skatista, baseado, sobretudo, no modo como interagem e enxergam a cidade, somado à forma lúdica de encarar sua prática. Mais importante que treinar é se divertir por meio do espírito for fun defendido por grande parte de seus praticantes.

Como veremos no decorrer do texto, a relação entre a essência skatista e o processo de "esportificação" aponta para uma dinâmica de aproximação e distanciamento do skate enquanto modalidade esportiva. Até que ponto a radicalidade e o risco presentes na prática do skate podem se adequar aos "princípios civilizatórios" de harmonia e organização da esfera pública?

\section{A EMERGÊNCIA DO SKATE E DOS ESPORTES RADICAIS}


Não existe uma data específica que marque o surgimento do skate. Algumas fontes chegam a determinar os anos de 1930 como o período em que os primeiros skates foram feitos artesanalmente nos Estados Unidos (Brandão 2011). No entanto, independente da data de origem, até o início da década de 1970 o skate não era ainda considerado propriamente uma "prática corporal esportiva", mas apenas um instrumento lúdico de brincadeira, "um entretenimento em que não havia tantos objetivos, como os de realizar manobras, vencer obstáculos, disputar competições ou mesmo viver profissionalmente do mesmo" (Machado 2014: 19). A combinação entre mudanças relacionadas a emergência dos esportes chamados originalmente de californianos (ou de aventura, e, mais tarde, radicais) e o modo como o skate passou a ser utilizado levou a uma nova dinâmica de sua prática a partir da passagem dos anos 60 para os 70 . Ou seja, foi a partir deste período que o skate passou a ser apropriado pelos jovens com o objetivo de produzir novas sensações no meio urbano por meio de práticas corporais que, de acordo com o tempo, passaram a produzir uma forma particular de seus praticantes experimentarem a cidade. Segundo o historiador Leonardo Brandão (2011), o desenvolvimento do skate como uma prática cultural produtora de um estilo de vida singular só foi possível graças a uma série de transformações que atingiram a sociedade ocidental nas últimas décadas do século XX. Sobre as mudanças no campo cultural o autor aponta que:

[...] houve um acelerado processo de aprimoramento de novos materiais e técnicas corporais que, conjugadas com um período de grandes revoluções culturais nas sociedades ocidentais, acabou por ramificar as atividades esportivas em práticas que se desenvolveram ligadas a movimentos juvenis e sem muita relação com os outros esportes de caráter já mais tradicional (Brandão 2011: 17).

Seguindo a abordagem de Elias e Dunning sobre a necessidade de entender o campo dos desportos e do lazer de maneira interdependente com a dinâmica mais ampla da sociedade, pode-se observar que a emergência dos esportes conhecidos hoje como radicais aconteceu em um momento de questionamento e abertura de novas possibilidades no campo cultural e esportivo. Até a metade do século $X X$ o campo esportivo tinha como parâmetro as modalidades tradicionais que, em sua grande maioria, surgiram no decorrer do século XIX como parte da dinâmica de consolidação da sociedade moderna baseada na revolução técnica - cientifica. As práticas esportivas surgidas no período refletiam os valores dominantes da sociedade industrial, pautados nos princípios da meritocracia (competição) e busca pela vitória por meio da organização tática, da técnica e da disciplina. Este era o comportamento esperado também dos proletários nas fábricas, assim como dos indivíduos na sociedade. O esporte, portanto, refletia o ideal positivista de que por meio da ordem, técnica e disciplina o indivíduo e a sociedade atingiriam o progresso. Trata-se enfim, de acordo com a perspectiva de Elias e Dunning, do processo de "esportificação" em que as práticas esportivas se configuraram como um dos instrumentos responsáveis pelo processo civilizatório na sociedade moderna.

Neste sentido, o advento dos esportes radicais na segunda metade do século XX não implica necessariamente o declínio das práticas esportivas tradicionais (e consequentemente da sociedade moderna do século XIX), mas seu surgimento deve ser encarado como um processo de reconfiguração das forças sociais que, no campo esportivo, apontou para uma crescente heterogeneidade de suas práticas (Stigger 2002). Segundo Christian Pociello (1995), 
desde o início estas novas práticas corporais se desenvolveram relacionadas a uma cultura adolescente voltada à transgressão das regras tradicionais. Práticas mais individualizantes, valorização do prazer, do hedonismo e a busca pelo risco podem ser consideradas as principais características que norteiam as práticas corporais que surgiram a partir da segunda metade do século XX. É importante ressaltar que neste mesmo período os jovens assumiram um crescente papel de protagonistas das transformações sociais em muitos países do mundo ocidental. A atuação política da juventude se espraiou por diferentes esferas da vida social questionando instituições, valores e costumes da época. A este conjunto heterogêneo de manifestações juvenis foi dado o nome de contracultura. Logo, a emergência dos esportes radicais pode ser encarada como parte deste movimento da contracultura no campo esportivo (Brandão 2011).

Foi neste contexto que o skate passou a se aprimorar como uma prática corporal a partir dos anos 70 . Contudo, seu desenvolvimento de um simples instrumento lúdico de lazer para um equipamento "esportivo" capaz de permitir aos jovens desenvolverem gestos acrobáticos, só foi possível graças a dois importantes fatores. O primeiro diz respeito às inovações tecnológicas nos materiais que compõem o skate, sobretudo a utilização de poliuretano na confecção das rodas (Britto 2000). Ao contrário dos materiais usados anteriormente, argila, ferro e borracha, o poliuretano permitiu que os skates se tornassem mais ágeis para realização das manobras e ao mesmo tempo oferecessem uma maior aderência ao solo, tornando-os mais seguros. Condições estas que permitiram um aumento na possibilidade de uso do skate para realização de manobras de uma forma mais arrojada e arriscada, potencializando assim a experiência do risco tão valorizada nos esportes radicais.

O outro fator fundamental para entender a dinâmica do skate refere-se à origem de muitos de seus praticantes. Em parte, o sucesso do skate entre os jovens nos anos 70 pode ser atribuído aos surfistas que passaram a utilizar os skates para realizar as manobras do surfe no asfalto em dias que o mar estava sem ondas, inclusive, "a prática do skate inicialmente foi chamada de sidewalk surfing, expressão que pode ser traduzida como 'surfe de calçada'" (Machado 2014: 20). Nos seus primórdios, portanto, o skate tinha uma forte ligação com o surfe, já que muitos de seus praticantes e manobras advinham desta modalidade. Para o historiador Leonardo Brandão (2011) a associação inicial com o surfe acabou sendo positiva, pois permitiu que o skate deixasse de ser encarado apenas como um instrumento lúdico e, aos poucos, passasse a ser reconhecido como uma prática corporal urbana com características próprias.

Tanto no Brasil como no exterior, sobretudo nos EUA, o skate no decorrer da segunda metade da década de 70 passou a atrair uma maior atenção do público juvenil. No caso brasileiro, como mostram Britto (2000) e Brandão (2011), revistas passaram a realizar reportagens sobre o skate e em pouco tempo publicações especializadas surgiram, assim como as primeiras pistas e competições. No entanto, neste momento o crescimento do skate ocorreu, em grande medida, em razão do investimento de marcas e empresas que viram em sua prática um novo nicho de mercado. Ou seja, não havia ainda sido consolidado um mercado e uma estrutura institucional criada e gerida pelos próprios skatistas. Sendo assim, a "cena do skate" neste primeiro instante estava muito presa ainda à cultura do surfe e dependente de empresas que enxergavam o skate como um campo de investimentos. 


\section{UMA PRÁTICA CORPORAL DISTINTIVAMENTE DA RUA}

A passagem para a década de 80 aponta para a crescente visibilidade de uma cena juvenil caracterizada pelo surgimento de diversas manifestações culturais que transformaram o espaço público em um espetáculo de estilos de vida expressos pela forma de se vestir, falar e comportar-se (Abramo 1996). Mais do que uma forma de rebeldia ou de alienação, estas manifestações representaram uma elaboração crítica de seu tempo. Segundo a socióloga Helena Abramo, dentre as diferentes manifestações do período, a que atingiu uma posição de maior destaque na cena juvenil foi o movimento punk. Além de ser um estilo musical, a cultura punk influenciou diversas áreas como moda, arte, design, cinema, poesia e comportamento político.

Para Leonardo Brandão a influência do movimento punk no skate aconteceu por dois vetores diferenciados: “por um lado as indústrias de skate passaram a apostar na estética punk para vender seus produtos" (Brandão 2011: 27), e, por outro lado, "foi possível notar que o anarquismo apregoado por este movimento [...] refletiu na prática do streetskate, especialmente nas apropriações transgressivas que os skatistas passaram a efetuar nos espaços urbanos" (idem). Foi neste contexto que o skate passou a redefinir suas características, na medida em que passou a se distanciar do surfe ao mesmo tempo em que incorporou parte do discurso estético dos punks na forma de se andar de skate e se relacionar com a cidade:

[...] existe uma semelhança entre a atitude do skatista de deambular por locais não projetados para sua prática com a atitude do movimento punk em negar qualquer tipo de imposição social. Em suas novas representações do urbano, os skatistas carregavam também um pouco do espírito utópico desse movimento, pois ambos enxergavam a realidade como algo possível de ser questionado, negado e refeito a sua própria vontade (Brandão 2011: 110).

Se nos anos 70 o skate se desenvolveu, em grande medida, vinculado à cultura do surfe, nos anos 80 , por sua vez, a situação mudou. A partir desta década os skatistas passaram a construir sua essência a partir da proximidade com a cultura punk. No livro $A$ onda dura: três décadas de skate no Brasil o skatista Fabio Bolota descreve as transformações que aconteceram no visual dos skatistas deste período no Brasil: "Sai o estilo freakheavymetal-cabeleira-surfe e entra o estilo agressivo eu-quebro-tudo-mesmo do punk-rock" (Britto 2000: 33). Ele lembra ainda que:

O Segundo Campeonato Brasileiro de Guaratinguetá foi um desfile de punks e simpatizantes. A cidade foi invadida por alfinetes e penteados que iam do moicano ao espigado ou pintado. Essa atitude começou a incomodar os moradores da pacata cidade, e logo após eles entraram em guerra contra os skatistas (Britto 2000: 33).

Foi nesta década que o skate dentro e fora do Brasil passou a construir um estigma relacionado a uma prática transgressora e avessa à ordem social. O novo visual, acompanhado de um comportamento considerado rebelde influenciado pelos punks, passou a redefinir os agenciamentos dos skatistas na cidade. A emergência da modalidade street, caracterizada pela apropriação criativa e desterritorializadora do mobiliário urbano, se transformou no símbolo de uma essência skatista que em sua gênese se contrapôs à lógica da "esportificação". Ou seja, ao 
invés de pacificar a esfera pública por meio de sua prática esportiva, o skate passou a se afirmar na cena urbano juvenil através da produção de conflitos, resultantes da forma alternativa com o qual passaram a "fazer cidade". 0 sociólogo José Machado Pais coloca esta questão do seguinte modo:

Os skaters fogem do atrito, mas a ocupação que fazem da rua afronta o convencional. De fato, o skateboard, libertando-se das convenções urbanas, viola a imposição que sustenta a necessidade de um recinto desportivo para a prática de um qualquer desporto clássico (Pais 2004: 14).

\section{A fala do skatista Marcos "ET" Ribeiro ilustra esta nova dinâmica criada pelo street skate:}

O skatista tem um olhar diferente sobre as coisas da cidade, os bancos das praças, as curvas da rua, as paredes inclinadas, escadarias, corrimãos [...] a arquitetura urbana é aliada ao espírito do skate (Marcos ET Ribeiro citado por Britto 2000: 77).

Neste sentido, a essência skatista passou a ser construída não como uma prática corporal esportiva, e sim como uma prática mais relacionada ao comportamento juvenil. Não é à toa que muitas das competições de skate do período aconteciam dentro de eventos maiores, envolvendo shows de bandas de rock. No entanto, o comportamento dos skatistas passou a ser identificado como uma forma de delinquência juvenil, pois como afirma David Matza:

Os delinquentes estão profundamente envolvidos numa incansável busca por excitação, de "sensação" ou de "emoções". O estilo de vida aprovado é o da aventura [...] ao cortejar o perigo físico, fazendo o que é proibido, e desafiando as autoridades, não está simplesmente se arriscando: está criando riscos, numa tentativa de produzir emoções (Matza 1968: 89 - 90).

Ao se apropriar do espaço urbano por meio da criação de riscos produtores de emoções, o skate então passou então a criar uma imagem associada à marginalidade e ao vandalismo. Afinal, a performance dos skatistas acaba desgastando e destruindo os equipamentos urbanos devido ao atrito provocado pelas manobras, além de sua presença, muitas vezes, afugentar os frequentadores habituais do espaço. Se para parte dos citadinos e autoridades o skate passou a adquirir um estigma negativo, por outro lado, os streeteiros, influenciados pelos ideais de rebeldia e transgressão presentes na cultura punk, trataram de positivar este estigma como sendo uma espécie de "traço diacrítico" da essência skatista. Até os dias de hoje muitos dos seus praticantes defendem que "é na rua que se anda de skate de verdade" (Machado 2014: 89). Ou seja, se a pista é o território de propriedade e direito dos skatistas, que oferece as condições ideais para sua prática esportiva, a rua, por sua vez, apresentase como o território da transgressão e dos desafios que extrapolam o limite da manobra. Na rua experimenta-se outro tipo de adrenalina e radicalidade, pois ela envolve o risco da apropriação criativa e transgressiva do espaço. Nesta perspectiva, a essência skatista não implica apenas andar de skate, mas, acima de tudo, envolve um tipo de comportamento e postura assim descrito pelo skatista Douglas Pietro:

Skatista mesmo, para mim, é o cara que já passou preconceito, já foi chamado de vagabundo, de moleque, de maloqueiro. O cara que perdeu uma mina do sonho porque não admitia vestir-se como ela queria, freqüentar 
os lugares que ela freqüentava. Que enfrentou constrangimentos na sala de casa, com a família achando tudo muito estranho. Skatista é o cara que leva o skate como estilo de vida, todo o tempo, o tempo todo. Além de, obviamente, andar de skate (Pietro 2012: 22).

Em sua pesquisa etnográfica sobre o street skate em São Paulo, Giancarlo Machado (2014) chama a atenção para o fato de que até os dias de hoje muitos skatistas se recusam a ser chamados de atleta, nem entendem sua prática como uma forma de treinamento. Para eles este tipo de classificação originalmente empregada nas modalidades esportivas tradicionais não guarda relação com a essência skatista. Ser skatista, nesta perspectiva, é colocar o skate no asfalto e encarar os desafios e riscos da cidade. Contudo, esta postura conflituosa acabou atraindo a atenção de forças normatizadoras da ordem social. Ainda nos 80 surgiram no Brasil as primeiras ações visando colocar o skate na ilegalidade como forma de conter as transgressões praticadas nas ruas. Como resposta à criminalização de sua prática, parte dos skatistas enxergou na institucionalização um caminho possível de legitimação e aceitação do skate pelo poder público.

\section{DA ILEGALIDADE À INSTITUCIONALIZAÇÃO}

No caso brasileiro um evento que pode ser considerado como símbolo da criminalização do skate ocorreu em São Paulo em 1988. Neste ano o então prefeito da cidade Jânio Quadros proibiu a prática de skate no Parque do Ibirapuera, um dos principais pontos de encontro de seus praticantes. O veto levou a uma série de manifestações por parte dos skatistas, o prefeito, por sua vez, acabou ampliando a proibição a todos espaços públicos da cidade. Frases como "skate não é crime!" e "skate, direito do cidadão, dever do Estado" passaram a ser estampadas em camisetas, shapes e revistas especializadas como lemas na luta por reconhecimento de sua prática na cidade. Em 1989, com a posse de Luiza Erundina como prefeita, os skatistas conseguiram negociar com o poder público a revogação da proibição.

Foi neste contexto de busca por descriminalizar sua prática que uma parcela dos skatistas, especialmente aqueles que estavam investindo na consolidação de um "mercado skatista", resolveram criar um corpo institucional capaz de canalizar os interesses do segmento. Desde 1987 já havia a tentativa de criar uma organização dos skatistas; este foi o caso da União dos Skatistas e Empresários (USE) que teve uma duração efêmera. Já em 1988, em razão da proibição do skate em São Paulo, começa a ser organizada a União Brasileira de Skate (UBS), que uma década mais tarde se transformaria na Confederação Brasileira de Skate (CBSK). Do final dos anos 80 até a primeira metade da década de 90 a UBS buscou se consolidar como uma estrutura formada por skatistas e empresários capazes de organizar o skate. Coube à UBS tratar das diretrizes relacionados à esfera esportiva: organização de campeonatos, criação de um ranking, capacitação de juízes e elaboração de um manual de regras. Já a articulação do mercado do skate, assim como a sustentação financeira da UBS, ficou a cargo da Associação Brasileira de Empresários de Skate (ABESK), cuja "filosofia de trabalho" era unir empresas de skate que têm suas raízes no esporte. O trabalho conjunto destas duas entidades permitiu que circuitos de 
campeonatos amadores e profissionais acontecessem no início dos anos 90 .

Além disso, a UBS manteve um canal de diálogo com o poder público, sendo que nos anos 90 um dos seus idealizadores, o empresário Alberto "Turco Louco", passou a exercer o cargo público de vereador e deputado estadual em São Paulo. Sua plataforma política tinha como bandeira principal a defesa do skate e dos esportes radicais. Em 1995 quando era vereador criou o dia municipal do skate, comemorado no dia 3 de agosto. Data que pode ser considerada como um símbolo da nova posição que o skate passou a almejar ocupar para além de uma manifestação juvenil caracterizada pela marginalidade. Para empresários e skatistas profissionais era chegada a hora do skate ser reconhecido como um esporte.

Nesta perspectiva, portanto, o skate passou a se distanciar dos ideais da cultura punk que inspiraram sua prática nos anos 80, pois, ao invés de negar o Estado e evitar qualquer tipo de cooptação pela a "ordem vigente", como prega o ideal anarquista, os skatistas, cada vez mais, começaram a se organizar por meio de associações de bairro, municípios e estados com o objetivo de estreitar o diálogo com o poder público para, sobretudo, viabilizar a construção de pistas destinadas exclusivamente à sua prática. Aqui é importante destacar que embora a essência skatista esteja em prática na rua, a pista costuma ser um local cobiçado e desejado por seus praticantes em razão das condições ideais oferecidas nestes locais. A arquitetura das pistas de skate é inspirada nos obstáculos que os skatistas buscam encontrar nas ruas, como corrimãos, bordas e transições, com o diferencial de que nestes espaços os obstáculos são destinados exclusivamente a sua prática. Se na rua é preciso enfrentar o risco da apropriação indevida do espaço, na pista, por sua vez, o risco é canalizado apenas para a radicalidade das manobras.

Na passagem dos anos 90 para a primeira década do século XXI o crescimento da visibilidade do skate foi acompanhado pela construção de inúmeras pistas pelo Brasil. No caso da cidade de São Paulo, especialmente durante a gestão da prefeita Marta Suplicy, foram construídas mais de sessenta pistas públicas na cidade. Desde então a prefeitura também passou a incentivar a realização de campeonatos de skate como ferramenta de inclusão social nas áreas de "vulnerabilidade social", como é o caso do Circuito Sampa Skate estudado por Giancarlo Machado (2014). De marginalizado nos anos 80, o skate passa então a ter uma "função social": se transforma em um instrumento de inclusão social e de combate a violência e a criminalidade nas periferias. Não é à toa que grande parte das pistas construídas pelo poder público está nestes territórios.

A construção das pistas de skate por parte do poder público pode ser entendida, portanto, como um processo de normalização e modelização do desejo. Embora proibições a prática de skate em determinados pontos da cidade continuem a acontecer, a canalização de seus praticantes a espaços pré-determinados não opera simplesmente por meio da repressão, pois é uma ação desejada pelos skatistas. As pistas oferecem condições ideais para o desenvolvimento técnico das habilidades em cima do skate. Neste contexto é possível dizer que as pistas passaram a exercer uma força de "esportificação" sobre seus praticantes, na medida em que o risco, a adrenalina e a radicalidade passaram a ser experimentados cada vez mais em espaços destinados exclusivamente à sua prática. Contudo, como mostra a pesquisa de Giancarlo Machado, a rua continua ainda a ser o local onde "se anda de skate de verdade", mas as pistas diminuem o ímpeto dessa apropriação, ao mesmo tempo em que passa a criar uma geração de pistoleiros (Machado 2012), categoria nativa que designa determinados skatistas 
que andam apenas em pista e que canalizam seus esforços visando bom desempenho em campeonatos e retorno financeiro por meio de patrocínios.

\section{O SKATE NA VIRADA DO SÉCULO}

O skate nos anos 90 passou por profundas transformações que vão bem mais além do que a construção de pistas. A maior institucionalização de sua prática propiciou também uma maior organização de seu mercado. Um dos objetivos com a criação da UBS foi também reunir empresários ligados ao universo do skate na intenção de reestruturar o seu mercado com base na idéia, muito forte até os diais atuais, de que o skate deve ser gerido pelos próprios skatistas (Britto 2000). Esta preocupação é resultado da experiência do final dos anos 80, em que o crescimento de sua prática não foi acompanhado pela estruturação de seu mercado, e sim pelo investimento de empresas "de fora do ramo" que passaram a usar a imagem do skate como um campo rentável de investimento (fato corrido também no final dos anos 70). Com a crise econômica do início dos anos 90 deflagrada pelo "Plano Collor", a maior parte destas empresas deixou de investir no skate levando ao fechamento de lojas, marcas, pistas e revistas especializadas. No início dos anos 90 o skate assistiu a uma forte retração de sua prática, apenas um pequeno número de skatistas continuaram a andar nas ruas. E foram eles que passaram a redefinir o modo de andar de skate no Brasil, como relata o skatista Marcos "ET" Ribeiro:

O skate perdeu a velocidade, as manobras se transformaram, parecia que uma garotada estava querendo criar um novo skate, voltado apenas para eles, sem direito a veteranos. A molecada assumiu uma postura radical, contra qualquer intromissão dos old schools. Eles sabiam de tudo, não aceitavam regras pré-determinadas, queriam reinventar tudo, muito inspirado em revistas gringas (Marcos "ET" Ribeiro citado por Britto 2000: 58).

O parágrafo acima aponta, em primeiro lugar, que, embora as transformações ocorridas no universo do skate no Brasil tenham sido influenciadas por um cenário mais amplo de crise econômica no país que acabou levando os skatistas a praticar nas ruas, mudanças na forma de andar de skate já vinham ocorrendo nos Estados Unidos e chegavam ao país através de revistas e vídeos de skate estrangeiros (gringos). Esta mudança, assim como aconteceu na passagem dos anos 70 para os 80 , resultou também no desenvolvimento de um novo design do skate. Visando atender os novos desafios que os skatistas passaram a criar em seu diálogo com a cidade, o skate passou a ser mais leve e ágil, de modo a facilitar a realização de um conjunto de novas manobras com maior grau de dificuldade e plasticidade.

Embora o espírito punk desenvolvido nos anos 80 ainda estivesse arraigado no modo pelo qual os skatistas se relacionavam com a cidade, houve uma mudança no estilo de como a nova geração dos anos 90 passou a encarar a prática de skate. A rua continuou sendo o local privilegiado para a realização das sessões, mas a técnica corporal empregada para andar de skate mudou. Se na década anterior as manobras valorizavam a velocidade e a agressividade como formas estilísticas de apropriação do espaço urbano, a partir dos anos 90 o estilo técnico 
passou a ser mais valorizado. O street incorporou a plasticidade das manobras de giro (como os flips, heelflips, varials, kickflips, que consistem em um conjunto de variações de movimentos em que o skate gira em torno de seu próprio eixo) executadas anteriormente só na modalidade freestyle, e passou a executá-las nos mais diversos obstáculos de rua, especialmente em transições, descidas de escadas e bordas usadas para o deslize. No freestyle estas manobras eram executadas apenas em plataformas lisas sem nenhum tipo de obstáculo.

Pode-se observar, portanto, uma metamorfose de estilos na "cena skatista". Nos anos 70 surgiu o estilo skate surfe, caracterizado pela transposição das manobras realizadas nas ondas pelos surfistas para o asfalto. $\mathrm{Na}$ década de 80 o estilo skate punk imprime um novo conjunto de práticas corporais baseadas, sobretudo, na exploração da arquitetura urbana. Já nos anos 90 o skate rap deixa sua prática mais técnica e amplia o campo de possibilidades de manobras a serem realizadas. Ou seja, se nos anos 70 as manobras se restringiam a "rasgadas" (slides) no asfalto, vinte anos depois as manobras se multiplicaram, assim como os locais em que são executadas. É importante ressaltar que estes diferentes estilos coexistem até os dias de hoje e influenciam, em grande medida, o modo de andar de cada skatista. Mais do que um conjunto de novas manobras, o skate rap também inovou no campo do comportamento juvenil. O fotógrafo de skate Guto Gimenez registrou do seguinte modo a associação entre skate e rap:

Marginal, agressivo, anti-social, rebelde, inúmeras vezes encontramos adjetivos como estes ligados ao skate. Até aí, nenhuma novidade. Mas quando estes mesmos adjetivos aparecem qualificando um novo estilo de música, e esta mesma música vêm alcançando um significativo sucesso, aí a coisa muda de figura. Com profundas raízes urbanas, letras fulminantes e um ritmo extremamente dançante, o rap não poderia encontrar um público melhor que os skatistas (Guto Gimenez citado por Britto 2000: 96).

A aproximação entre as duas manifestações levou a criação de uma nova estética juvenil, chamado por alguns de seus praticantes como gangueiro, e que ficou conhecido no campo da moda como streetwear, ou moda de rua. Roupas largas, coloridas, com desenhos grafitados, calças abaixo da cintura, gorros e bonés compunham este novo visual que contrastava com o visual dos anos 80 inspirado na cultura punk. A novidade do estilo streetwear na cena urbana juvenil passou a chamar a atenção de setores da indústria cultural. Rapidamente, o skate no decorrer da década de 90 passa por uma nova fase de crescente visibilidade de sua prática. No entanto, ao contrário das décadas anteriores, o skate agora estava mais organizado para capitalizar esta visibilidade a seu favor, sobretudo em decorrência da criação da UBS e da CBSK em 1999. Outros fatores a levar em consideração dizem respeito ao crescimento do skate nas periferias urbanas, especialmente em decorrência da aproximação com a cultura hip-hop, e à entrada das camadas populares no mercado consumidor.

Neste contexto, portanto, o skate passou a conquistar, tanto no Brasil como fora do país, uma crescente visibilidade em diversos campos da vida social. O skate passou a influenciar campos com que tradicionalmente já mantinha um vínculo, como as áreas relacionadas ao comportamento juvenil e aos esportes de ação, mas também passou cada vez mais estar presente em novas áreas, como a arte, arquitetura, urbanismo e políticas públicas. Programas esportivos e voltados ao entretenimento do público jovem passaram também a dar visibilidade ao skate. 
maior atenção da mídia esportiva. Logo, pode-se dizer que o skate na virada do século atingiu sua "maturidade": cada vez mais a lógica da "esportificação" passa a influenciar a "cena skatista", como mostra o comparativo do skate no Brasil entre 1995 e 2000 publicado sob o título "Reflexões sobre os últimos cinco anos de skate brasileiro" na revista Cemporcento Skate (Caruso 2000):

- EMPRESÁRIO. Em 1995: pagava pouco e patrocinava poucos atletas. Alguns, por falta de condições, outros por não acreditarem ainda no skatista como principal ferramenta de marketing. Em 2000: passa a ter consciência de que o mercado gira em torno do esporte e que o atleta é o principal elemento. As marcas mais estruturadas já contam com um "team manager" (chefe de equipe).

- SKATISTA. Em 1995: faltava um pouco de consciência de seu papel no mercado. Em 2000: o skatista amadureceu. Adquiriu uma postura que traz como reflexo atletas mais profissionais e, conseqüentemente, uma imagem mais positiva sobre o esporte.

- CIRCUITO PROFISSIONAL. Em 1995: se desse acontecia, não havia calendário fechado. Premiações baixas e péssima organização. Em 2000: melhores premiações. Maior consciência dos organizadores. Início de trabalho de um órgão (CBSK) que oficializa o circuito e busca melhorar a organização e julgamento.

- MÍDIA ESPECIALIZADA. Em 1995: havia apenas uma revista, alguns fanzines e vídeos. Em 2000: mais atuante e periódica. Além de revistas grandes e mais vídeos, a mídia especializada se instalou na televisão e internet.

Logo, o skate na virada do século passou a se organizar com o objetivo de conquistar uma maior profissionalização e reconhecimento, para além dos de seus praticantes. Esta iniciativa acabou aproximando-o da dinâmica que envolve os grandes eventos esportivos e, para alguns, a inserção na lógica do mercado esportivo pode colocar em risco a essência skatista forjada nas ruas.

\section{POLÊMICA SOBRE A PARTICIPAÇÃO DO SKATE NOS JOGOS OLÍMPICOS}

Um espectro ronda o skate: o espectro das Olimpíadas. A polêmica e ainda hipotética entrada do skate no rol dos esportes olímpicos é uma questão que já vem sendo levantada desde os Jogos de Atlanta (1996), mas que ganhou uma dimensão maior somente nos anos 2000, quando o COI (Comitê Olímpico Internacional) passou a tratar o assunto com mais ênfase [...]. Em ano de Olimpíada o tema aparece com mais freqüência - tanto na mídia como nas rodas de conversas nas sessóes - e a controvérsia volta à tona, como foi o caso agora, durante os Jogos Olímpicos de Londres 2012 (Viegas 2012: 56).

O trecho citado acima faz parte de um artigo publicado na revista Cemporcento Skate, em que é discutida a possibilidade de inserção do skate nos Jogos Olímpicos. Quais seriam as vantagens e desvantagens da participação do skate em eventos deste gênero? Para debater o tema a revista buscou pontos de vista sobre como diferentes pessoas envolvidas com o skate enxergam esta questão. O ponto central da discussão foi em relação aos perigos que a inserção em um evento esportivo deste porte pode acarretar ao skate, especialmente no que diz respeito à 
manutenção da essência skatista. Para Marcelo Viegas, que assina o artigo, a desconfiança dos skatistas passa pelo perigo que a organização do skate saia da mão dos skatistas, pois segundo o autor "o skate construiu sua grandeza através de suas próprias forças. A paixão de cada pessoa que já colocou os pés sobre um skate é o alicerce desse prédio muito bem edificado" (Viegas 2012: 57).

Como visto no decorrer do texto, existe uma preocupação em manter o "skate nas mãos dos skatistas". A polêmica em torno de sua participação nos Jogos Olímpicos passa em grande medida por esta questão, que, por sua vez, coloca em debate o modo como seus praticantes entendem e ressignificam a essência skatista para "além da rua". Ou seja, como é possível o skate manter aquelas suas características que extrapolam os limites de uma prática esportiva ao participar de eventos que primam pela "esportificação" das modalidades? Quais os benefícios que os Jogos Olímpicos podem trazer ao skate? Antes de explorar mais detidamente estas questões, é importante ressaltar que a polêmica em torno de uma maior "esportificação" do skate já é debatida na esfera cotidiana de seus praticantes, sobretudo a partir do momento em que a construção de pistas e a proliferação de competições amadoras e profissionais fortaleceram a perspectiva propriamente esportiva de sua prática.

Como mostra a pesquisa de Giancarlo Machado, a importância dada aos campeonatos por determinados skatistas, assim como a exclusividade de sua prática nas pistas, levou a criação de uma categoria acusatória no meio do skate referente a este tipo de praticantes. Os skatistas que andam apenas em pistas e se preocupam apenas com o desempenho em campeonatos e na aquisição de patrocínios, são classificados pejorativamente de pistoleiros, ou seja, são praticantes que não agem de acordo com a essência skatista, voltada à rua e à diversão (for fun). Segundo o autor existe uma relatividade nesta acusação, pois não há problema em andar nas pistas, mas sim em restringir sua prática a este tipo de espaço e não encarar os desafios e riscos existentes na rua. Afinal, para um segmento de skatistas é na "rua onde se anda de skate de verdade". Nesta perspectiva, para ser reconhecido não basta ganhar campeonatos, mas acima de tudo é preciso mostrar sua habilidade (base) nas ruas. Sendo assim o pistoleiro passa a ser visto como alguém que não mantém uma relação for fun com o skate, sua postura é de um atleta em busca do aprimoramento técnico e competitivo:

Muitas vezes a figura do pistoleiro associa-se à do skatista "campeonateiro", isto é, aquele que se centra no treinamento exaustivo de manobras para as competições em espaços que apenas simulam os obstáculos encontrados nas ruas e nem sempre se diverte com a prática do skate. Sendo assim o que mais importa para esse tipo de praticante é o aperfeiçoamento por meio da competição, a fim de incorporar a técnica necessária para o exercício da prática esportiva, tendo em vista a busca por resultados práticos (Machado $2012: 11$ - 12).

Um pistoleiro só é bem visto por seus pares quando ele demonstra ser um skatista overall, característica daqueles que andam nas pistas, mas que também demonstram ter a base nas ruas. Esta "tensão" entre pista e rua pode ser interpretada como resultado da própria dinâmica do skate a partir dos anos 90 . Por um lado, a proliferação de pistas e campeonatos evidencia uma maior organização do fluxo de skatistas na cidade. A relação conflituosa de apropriação com a rua passa a sofrer uma força gravitacional exercida pelas pistas, que se configuram como espaços disciplinadores de sua prática. A nova geração de skatistas que surgiu na virada do século passou desde o cedo a se acostumar a andar em pistas. Soma-se o fato ainda que o crescimento do mercado e a 
maior profissionalização permitiram que muitos praticantes passassem a vislumbrar um possível futuro no skate para além do for fun. Portanto, para os pistoleiros andar de skate passe a ser, sobretudo, uma forma de treinamento esportivo. Sua relação com o skate é a de um atleta. Para este tipo de skatista a definição de Douglas Pietro (2012: 12) de que skatista "é o cara que já passou preconceito, já foi chamado de vagabundo, de moleque, de maloqueiro" deixa de ter um sentido prático relacionado ao modo como se interage no espaço urbano. De "maloqueiro" só resta o estereótipo.

É importante ressaltar o papel da CBSK neste processo, pois dentre os diferentes marcos regulatórios construídos pela entidade existe um tópico relacionado a disciplina e ao comportamento dos skatistas durante as competições, dentro e fora da pista. Até os anos 90 eram comuns os relatos de competições marcadas pela desorganização e a algazarra praticada pelos skatistas nos locais onde aconteciam as competições. Confusões, bebedeiras e atrasos eram considerados como parte do espírito for fun e do comportamento "maloqueiro" dos skatistas. Em muitos casos, as reportagens escritas para as revistas de skate davam uma maior ênfase às confusões geradas pelos skatistas na cidade onde ocorria o evento. A competição em si ficava em segundo plano.

Com a regulamentação disciplinar da CBSK este tipo de atitude "não profissional" passou a ser coibida. $\mathrm{O}$ objetivo da entidade foi melhorar a organização dos eventos, fator importante para atrair patrocinadores, assim como criar um senso de responsabilidade e de profissionalização dos skatistas. Atualmente, as reportagens sobre campeonatos costumam realizar um olhar mais técnico, o foco passou a ser a análise propriamente esportiva. Qualidade da organização e da pista, premiação e o desempenho técnico dos skatistas (atletas) costumam ser os temas centrais das reportagens. A desorganização e confusões passam ser retratadas de forma pejorativa: se transformam em sinais de amadorismo e falta de profissionalismo. Mesmo com a maior profissionalização o espírito for fun continua a ser valorizado, porém não mais como uma atitude de "maloqueiro". Como mostra a pesquisa de Machado (2014), o for fun é valorizado como eixo da sociabilidade entre os competidores durante o evento, em que mais importante do que ganhar é estar junto de seus pares, andando de skate.

Pode-se dizer, portanto, que as transformações que dinamizam a prática do skate se articulam em torno das polaridades rua versus pista, diversão versus treinamento, skatista versus atleta, que, por sua vez, guardam relação com o processo de maior mercantilização e "esportificação" que o skate vem atravessando nos últimos tempos. Para ser reconhecido e expandir sua prática o skate precisou se organizar e criar canais de como explorar sua radicalidade e seu espírito for fun para além da rua.

A participação em grandes eventos esportivos passou a ser uma forma de o skate ampliar seus horizontes. A presença nos X-Games (conhecido também como as Olimpíadas dos esportes radicais) como uma das principais atrações, pode ser considerada como um marco da inserção do skate no universo dos grandes eventos esportivos. Criada nos Estados Unidos pelo canal de televisão ESPN durante os anos 90, esta competição buscou criar uma alternativa rejuvenescida aos Jogos Olímpicos tradicionais. Ao invés de modalidades esportivas seculares e de pouco apelo no grande público, especialmente para os jovens, os X-Games investiram na plasticidade e no espetáculo que a radicalidade dos esportes radicais podem propiciar. Por se tratar de um evento organizado por grandes empresas e não por entidades esportivas, duas de suas principais marcas são a flexibilidade e ausência 
de normas rígidas. Ou seja, não há uma padronização que nivele as diferentes modalidades ou que restrinja sua participação. Por focar-se essencialmente nos interesses comerciais e de audiência, o que se explora neste tipo de evento são a novidade e os limites da radicalidade.

Devido ao sucesso dentro e fora dos Estados Unidos, os X-Games se globalizaram e passaram a ser realizados anualmente em diversas regiões do mundo, inclusive no Brasil. Este evento, tanto para o skate como para os demais esportes radicais participantes, propiciou um aumento de projeção e atraiu cada vez mais a atenção para este tipo de modalidades. Cada vez mais o Comitê Olímpico Internacional (COI) e seus patrocinadores passaram avaliar a possibilidade de incluir modalidades radicais nos Jogos Olímpicos. O snowboard (esporte de prancha similar ao skate e ao surfe, mas praticado na neve), por exemplo, foi recentemente incorporado aos Jogos Olímpicos de Inverno. Em 2011 o COI cogitou incluir o skate como uma modalidade olímpica já nos Jogos do Rio de Janeiro de 2016. A notícia acabou trazendo uma polêmica no meio do skate entre os favoráveis e os críticos a sua participação em um evento deste porte. Para os skatistas simpáticos a esta proposta, a inclusão do skate pode trazer credibilidade, além de expandir o seu mercado, como opina o skatista brasileiro da modalidade vertical Rony Gomes:

Seremos mais respeitados e teremos uma visibilidade muito maior, com isso mais pessoas irão andar de skate e conseqüentemente mais gente investindo em nosso mercado, mais patrocinadores, mais skateparks (Rony Gomes citado por Viegas 2012: 59).

É importante ressaltar que este depoimento foi dado por um skatista da modalidade vertical, cuja prática ocorre exclusivamente em pistas onde existem half-pipes. Devido a sua plasticidade, historicamente o vertical sempre foi a modalidade que atraiu mais a atenção da grande mídia e do público de fora do skate. Dentre as diferentes modalidades, ela é a que se melhor se enquadra nos parâmetros esportivos. Caso não sejam skatistas overall, os verticaleiros acabam sendo também rotulados como pistoleiros pelos "praticantes da rua". Sendo assim, a fala de Rony Gomes está alinhada à perspectiva de que quanto mais o skate se assumir enquanto uma modalidade esportiva, maior é a possibilidade de o skate crescer e aumentar sua estrutura.

Para os skatistas contrários à perspectiva de uma maior "esportificação" de sua prática, a participação nos Jogos Olímpicos não traria vantagens ao skate. Para o skatista profissional estadunidense Tony Hawk, "os Jogos Olímpicos precisam mais do skate do que o skate precisa dos Jogos Olímpicos" (Viegas 2012: 57). Ou seja, mais do que um desejo do skate em ser reconhecido, a participação nos Jogos Olímpicos é uma demanda do próprio $\mathrm{COI}$, que possui interesses comerciais nesta aproximação. Segundo o skatista profissional Neil Hendrix, a primeira vez que houve uma sondagem sobre este tema ocorreu nos anos 90, durante os Jogos de Atlanta, em 1996:

A coisa toda começou através do COI e da NBC, que é a emissora de televisão que transmite os Jogos Olímpicos nos EUA. Ambos perceberam que precisam atrair o interesse da juventude para as Olimpíadas, porque todos os esportes olímpicos estão envelhecidos e 'cansados', não interessam a juventude de hoje (Neil Hendrix citado por Viegas 2012: 57).

As falas tanto de Tony Hawk como de Neil Hendrix acenam para uma questão central que envolve a 
aproximação do skate com os Jogos Olímpicos: se por um lado a participação em um evento deste porte pode trazer reconhecimento e potencializar o mercado do skate, por outro o interesse do COI (e de seus parceiros patrocinadores) é usar a imagem do skate, assim como de outras modalidades de esportes radicais, com o objetivo de renovar a imagem dos Jogos e atrair a atenção do público jovem. Os esportes radicais possuem uma dinâmica diferenciada dos esportes tradicionais:

Por ter nascido na contracultura (e permanecer nela, pelo menos em diversos aspectos) e ter esse respaldo da juventude, o skate pode injetar nas Olimpíadas um elemento que os americanos chamam de 'cool factor'. O skate é legal, é 'cool', e, segundo Tony Hawk, as Olimpíadas precisam disso (Viegas 2012: 57).

De certo modo o chamado "cool factor" presente na prática do skate, que pode ser interpretado como sendo o espírito for fun valorizado pelos skatistas, cria uma variação no "fair play" valorizado nos esportes tradicionais, em que a competição deve seguir princípios civilizados de respeito ao adversário. No caso do skate o "fair play" ganha uma dimensão lúdica, pautada na perspectiva segundo a qual "o que vale é não competir" (Machado 2014). Ou seja, de acordo com o espírito for fun, o skatista não compete contra um adversário, mas sim contra o limite de seu corpo, e na busca por realizar uma boa linha que arranque aplausos de seus pares (Yeah!). Não são bem vistas no meio do skate atitudes como torcer para que outro skatista erre suas manobras:

O skate teria bastante a acrescentar ao tal espírito olímpico. Skatistas finalizam suas voltas e, caso tenham feito aquilo que queriam, sentem-se vitoriosos. As posteriores decisões dos juízes podem até decepcionar, mas não fazem o mundo cair. Uma ginasta faz uma ótima apresentação, sai sorridente. O técnico vibra. O ginásio ovaciona. Após a exibição dos frios números por parte dos juízes, a festa vira tragédia. Choro, desespero e decepção. Cadê a alegria e a satisfação de instantes atrás? Nessa realidade, a consciência do juiz é mais importante do que a do próprio competidor. O fato é que nós, skatistas, sabemos que competir não é passar por cima, tampouco destruir ninguém (Viegas 2012: 59).

Em pesquisa realizada anteriormente (Olic 2010), descrevo etnograficamente como se tecem as relações entre os skatistas em pistas e picos da cidade. Em muitos casos a competição está ligada mais a questões de territorialidade e localismo, que indicam a formação de redes de sociabilidade mais densas de pertencimento entre seus praticantes, do que propriamente ao rendimento de cada skatista. No campo de sua prática corporal ("esportiva"), pode-se observar que a relação não é pautada a partir da lógica competitiva tradicional, marcada, sobretudo, por uma dinâmica que parte de uma condição de simetria inicial (zero a zero) e o jogo se encerra com uma situação de assimetria em que se definem os vencedores e os derrotados. Pode-se dizer que os skatistas constroem um jogo relacional de vidente e visível expresso pelo termo nativo yeah!, que é proferido quando um de seus pares acerta uma manobra. Neste jogo o skatista cumpre um duplo papel, ora é o sujeito da ação (recebe o yeah!), ora é o sujeito da observação (emite o yeah!). Assim, o que para os leigos parece a princípio apenas um grito sem significado, para os skatistas expressa um conceito empírico de manutenção de uma condição de igualdade, e de valorização do espírito for fun em detrimento dos ideais de meritocracia presentes nos jogos competitivos tradicionais. 
A valorização do for fun e de uma isonomia pautada na reciprocidade acaba trazendo, portanto, um impasse quanto à possível inserção do skate nos Jogos Olímpicos. Por um lado, sua prática poderia trazer o espírito for fun ("cool factor"), por outro, a possível ingerência do COI na regulação sobre a organização da competição poderia comprometer a essência skatista. Caso os skatistas não participem da organização, correm o risco de sua prática ser descaracterizada. Este parece ser um ponto de preocupação mesmo entre aqueles que são favoráveis ao ingresso do skate nos Jogos:

Se o skate for gerido por skatistas e contar com skatistas profissionais de primeira linha de todas as partes do mundo. Veja como são gigantescos eventos como o X-Games, Dew Tour e Maloof Money Cup. O skate já virou um grande show para a televisão. O problema com as olimpíadas é que existe toda uma questão política e burocrática que torna ainda mais difícil (Neil Hendrix citado por Viegas 2012: 59).

A questão política e burocrática a que se refere Neil Hendrix diz respeito às exigências do COI, que estipula uma série de normativas como pré-requisitos para o ingresso da modalidade nos Jogos Olímpicos. Uma das principais exigências é a necessidade de haver entidades representativas do esporte nos diferentes continentes. No caso do skate não existe uma estrutura deste gênero, como relata o vice-presidente da CBSK Ed Scander:

O skate, pelo seu histórico e metodologia de se organizar, dependendo mais da iniciativa privada, tem menos entidades regulamentadoras (associações, federações, confederações) do que os esportes tradicionais [...] não existe uma federação ou confederação européia, asiática ou africana, ou ainda, das Américas. Portanto, se as entidades de skate não se unirem e fundarem sua federação continental, não será possível cumprir esta regra do COI (Viegas 2012: 57).

Embora no Brasil o skate tenha se organizado por meio da criação de uma Confederação que representa institucionalmente o skate, em outros países, como os Estados Unidos, não há este tipo de estrutura centralizadora que normatize sua prática. Em muitas localidades o skate é organizado e gerido pelas empresas que realizam as competições e patrocinam os skatistas. Não há uma demanda junto ao poder público com o objetivo de incentivar sua prática. No entanto, em 2005, “com receio que a administração do skate mundial caísse nas mãos de quem não fosse do meio" (Ed Scander citado por Viegas 2012: 57) foi criada a primeira entidade internacional de skate agregando 32 países: a International Skateboarding Federation (ISF). A entidade surgiu como uma espécie de resposta ao risco de o skate ser cooptado a participar de grandes eventos esportivos sem passar pelo crivo dos skatistas. Segundo Marcelo Viegas, "a atuação da ISF é direcionada no sentido de preservar a essência do skate se de fato um dia ele entrar nos Jogos Olímpicos. Garantir sua legitimidade e manutenção de suas características" (Viegas 2012: 57). Para Marcelo Santos, presidente da CBSK, caso o skate participe dos Jogos Olímpicos, o ingresso deve acontecer por meio da intermediação dos próprios skatistas:

Para a CBSK o skate somente deve ser incluído nas Olimpíadas se o controle das regras, administração, arbitragem e fiscalização estiverem a cargo de skatistas. A confederação não aceita uma entidade internacional que não seja formada e gerida por skatistas para a tarefa de tornar o skate um esporte olímpico. Portanto a CBSK apenas apoiaria o skate nos Jogos Olímpicos se a ISF fosse encarregada da tarefa (Marcelo Santos citado por Viegas 2012: 57). 
Sendo assim, os skatistas receberam de forma pessimista a última investida do COI para viabilizar o ingresso do skate nas olimpíadas do Rio de Janeiro. Como o skate não possui ainda entidades representativas em cada continente, o COI sugeriu que a ISF se articulasse com a Union Cycliste Internationale (UCI), entidade que representa diferentes modalidades olímpicas de ciclismo, com o objetivo de criar um "caminho legal" para que o skate pudesse participar do evento. Contudo, segundo Marcelo Santos "a ideia não vingou pela resistência dos skatistas do esporte ser regulamentado/administrado por uma entidade que não seja do skate" (Viegas 2012: 57). Nesta perspectiva, o ingresso pela $\mathrm{UCl}$ representaria justamente o que os skatistas mais temem, a possível perda do controle sobre a organização do skate. Ao "sair da mão dos skatistas" o skate, segundo seus praticantes, pode correr o risco de perder suas características, pois, como coloca Marcelo Viegas, "a preocupação de todos, tanto os que apóiam quanto os que questionam, é manter intacta a essência do skate" (Viegas 2012: 59).

Mesmo para aqueles que vêem com simpatia a participação do skate nos Jogos, como o skatista Rony Gomes, a manutenção da essência skatista passa pela condição de "que não mudem os regulamentos da competição. $\mathrm{E}$ também que os skatistas não tenham que usar um uniforme como qualquer outra modalidade, e sim um específico do skate" (Viegas 2012: 59). Aqui nota-se que a ideia de essência skatista está vinculada basicamente à sua prática esportiva. Trata-se, portanto, da visão de um potencial pistoleiro que, por sua vez, diverge da perspectiva de um streeteiro de rua. Para aqueles que acreditam que é "na rua onde se anda de verdade" o skate não pode ser enquadrado como uma prática esportiva, de modo que a participação nos Jogos Olímpicos representa uma descaracterização de sua prática. Na visão do skatista Adelmo Júnior o skate estaria mais próximo de uma expressão artística do que propriamente de uma modalidade esportiva tradicional:

Sou contrário por não ver algo bom para o skate com regras, uniformes e números de competidor no peito. O skate já passou por isso e evoluiu para algo muito maior que um esporte: um movimento que tem sua identidade própria e se recicla constantemente, livre de conceitos únicos e regras. O skate é infimamente artístico (Viegas 2012: 59).

Marcelo Viegas complementa o depoimento de Adelmo Júnior ao afirmar que o skate possui "conexões mais próximas com algumas expressões artísticas do que propriamente com uma atividade esportiva tradicional" (Viegas 2012: 56). Nesta perspectiva, a incompatibilidade entre o skate e os grandes eventos esportivos reside no fato de que:

O skate parece conter algo a mais do que um esporte: ao invés de estarem em pistas treinando para campeonatos, muitos skatistas preferem arriscar manobras nas ruas, correndo o risco de sofrerem acidentes e sujeitos a serem expulsos dos lugares nos quais transitam, criando problemas com guardas de trânsito, policiais e transeuntes. Ao invés de usarem uniformes para representarem suas equipes, municípios ou Estados, eles se vestem como cantores de rock, hip-hop ou demais gêneros musicais (Brandão 2011: 21).

A discussão em torno da participação do skate nos Jogos Olímpicos passa, portanto, pelo entendimento do que seus praticantes consideram como sendo a essência skatista, e de até que ponto esta essência forjada nas 
ruas e pelo espírito for fun pode coexistir com a dinâmica de "esportificação", que, por sua vez, além de garantir reconhecimento à sua prática, permite também que mais skatistas possam viver dela, seja por meio de patrocínios, seja através do ingresso no mercado relacionado ao skate.

\section{CONSIDERAÇÕES FINAIS: DE VOLTA ÀS RUAS}

Comparada com outras modalidades esportivas tradicionais, o skate pode ser considerado uma prática corporal recente no cenário urbano. Sua breve história acompanha de forma singular as transformações que vêm ocorrendo na sociedade contemporânea. A relação entre prática esportiva e comportamento juvenil parece ser uma das principais características que diferenciam estas novas modalidades corporais. A emergência dos esportes radicais aponta para uma nova dinâmica em que a atividade física está relacionada também à construção de um estilo de vida que orienta o comportamento daqueles que ingressam nestas atividades. No caso do skate, a produção de um estilo de vida em torno de sua prática aconteceu de uma maneira processual. Por meio de bricolagens com outras manifestações juvenis (surfe, punk, hip-hop) aliadas ao modo como se apropriam da cidade, seus adeptos passaram a construir para si uma essência skatista, que passou a diferenciá-los das demais culturas juvenis e modalidades esportivas.

Concomitante a esta dinâmica de interação no espaço público que acabou forjando uma essência skatista, o skate, assim como os demais esportes radicais, aos poucos foi ganhando maior reconhecimento e visibilidade. Para que esta visibilidade não se configurasse como um fenômeno efêmero da moda, o skate (sobretudo a partir dos anos 90) passou a se institucionalizar com o objetivo de capitalizar e potencializar sua prática. Este processo pode ser descrito como uma dinâmica de "esportificação", que, dentre outras coisas, permitiu ao skate legitimarse como uma modalidade esportiva. A participação do skate em grandes eventos esportivos e o debate sobre sua participação nos Jogos Olímpicos é resultado deste processo de maior visibilidade.

Contudo, entre os skatistas a dinâmica de "esportificação" é acompanhada de forma crítica, especialmente no que se refere ao perigo do "skate sair da mão dos skatistas" e da descaracterização da essência skatista. Caso isto ocorra, segundo seus adeptos, existe o risco de o skate perder sua singularidade e se nivelar às demais modalidades esportivas. Para equacionar esta questão, aqueles que enxergam os benefícios que a "esportificação" pode trazer ao skate argumentam que o risco de perda da essência skatista depende fundamentalmente da manutenção do "skate na mão dos skatistas". Nesta perspectiva, não há nenhuma contradição em encarar sua prática como uma modalidade esportiva, pois as competições sempre existiram e são uma forma de garantir retorno financeiro para seus praticantes. Basta que toda organização fique a cargo dos skatistas, que sabem lidar com as peculiaridades deste segmento. Por outro lado, os críticos a esta posição avaliam que o skate não pode se enquadrar como uma modalidade esportiva, pois sua prática refere-se essencialmente ao espírito for fun, desenvolvido na rua. Daí a visão negativa de parte dos skatistas para com os pistoleiros. Ao se restringirem às pistas e encararem as sessões como treinos, estes skatistas estariam deturpando a essência skatista.

A dinâmica do skate, portanto, é marcada por esta "tensão" entre uma dimensão voltada mais aos 
campeonatos e as pistas, e outra perspectiva que valoriza mais a diversão e a rua. Muitos skatistas, especialmente os da modalidade street, por mais que participem de campeonatos e conquistem boas colocações, só passam a ser reconhecidos por seus pares quando mostram sua base na rua. Para os streeteiros a participação em vídeos de skate ou ter sua foto publicada em uma revista especializada vale mais do que o desempenho em competições. Se nos campeonatos é valorizado, sobretudo, o desempenho técnico do skatista em um momento específico, nos vídeos e fotos, além da técnica, o lugar onde são executadas as manobras é um elemento determinante para a valorização da imagem. Aqui o skate entra em um campo em que prática esportiva e artística se misturam. Nos vídeos e fotos não se trata de um skatista vencer o outro, como funciona na lógica esportiva dos campeonatos, mas o que é valorizado é o registro da relação criativa que o skatista estabelece com a cidade. Uma boa imagem é aquela que alia a plasticidade da manobra com o local da cidade em que ela é realizada.

Mesmo com a construção de inúmeras pistas e a proliferação de campeonatos os skatistas continuam a se dirigir às ruas. Todavia, como sugere a pesquisa de Giancarlo Machado, muitos skatistas que saem às ruas com câmeras fotográficas e filmadoras passam a estabelecer uma nova relação com o espaço público. Se antes a rua era o local por excelência do espírito for fun e da diversão, para os skatistas que buscam sobreviver de sua imagem, as sessões na rua passam a ser encaradas como uma forma de trabalho. Captar uma boa imagem em um local onde nenhum outro skatista andou, ou realizar uma manobra nunca antes registrada em determinado pico skatável, pode garantir visibilidade, reconhecimento e possíveis patrocínios ao skatista. Ao encarar a prática do skate na rua como uma forma de trabalho, estes skatistas descritos na pesquisa de Giancarlo Machado buscam se desvincular da imagem do skate como uma prática transgressora e conflituosa da ordem urbana. A ocupação da cidade deixa de ser uma ação desinteressada e passa a ser tratada como um ofício. Inclusive, esse passa a ser o discurso mobilizado na negociação para usar determinados espaços: eles não estão ali para se divertir, mas sim para trabalhar.

Esta nova postura dos skatistas na cidade suscita uma questão para encerrar o texto: seria esta uma estratégia dos skatistas para sobreviver de forma alternativa ao processo de "esportificação"? Ou, pelo contrário, esta "relação profissional com a rua" é um indício de normatização da postura dos skatistas para além das pistas e campeonatos?

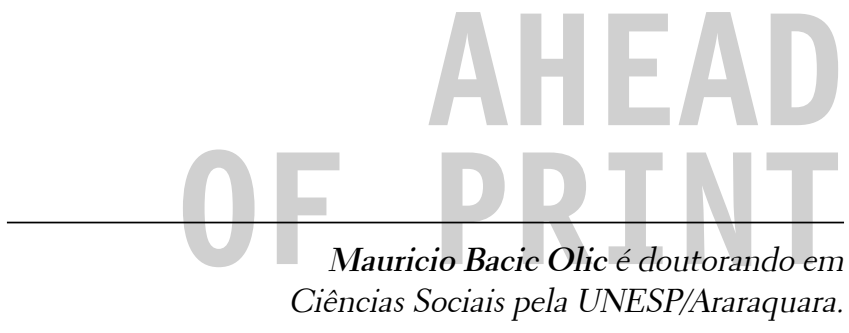




\section{REFERÊNCIAS BIBLIOGRÁFICAS}

ABRAMO, Helena. 1994. Cenas Juvenis: punks e darks no espetáculo urbano. São Paulo: Página Aberta/ANPOCS.

BRANDÃO, Leonardo. 2011. A cidade e a tribo skatista: juventude, cotidiano e práticas corporais na história cultural. Dourados: Editora UFGD.

; HONORATO, Tony (orgs). 2012. Skate e skatistas: questões contemporâneas (Apresentação). Londrina: EdUEL.

BRITTO, Eduardo (org.). 2000. A onda dura: três décadas de skate no Brasil. São Paulo: Parada Inglesa.

CARUSO, Reinaldo. 2000. "Reflexões sobre os últimos cinco anos do skate brasileiro". Cemporcento Skate 30: 34 - 45.

DIMENSTEIN, Gilberto. 2002. “Capital do skate”. Folha de S. Paulo, Caderno Cotidiano. São Paulo, 19/06/2002.

DUNNING, Eric; ELIAS, Norbert. 1992. A busca da excitação. Lisboa: Difel.

MACHADO, Giancarlo. 2012. “Dilemas em torno da prática de skate em São Paulo". Esporte e Sociedade 19: 3 - 18. . 2014. De "carrinho" pela cidade: a prática do skate em São Paulo. São Paulo: Intermeios/FAPESP.

MATZA, David. 1968. "As tradições ocultas da juventude". In: S. Britto (org.) Sociologia da juventude. Rio de Janeiro: Zahar.

OLIC, Mauricio Bacic. 2010. Entre o liso e o estriado: skatistas na metrópole. Dissertação, Programa de Pós-Graduação em Ciências Sociais. Pontifícia Universidade Católica de São Paulo.

PAIS, José Machado. 2004. Tribos urbanas: produções artísticas e identidades. São Paulo: Annablume.

PIETRO, Douglas. 2012. “Quem é skatista”. Revista Cemporcento Skate 175: 22.

POCIELLO, Christian. 1995. “Os desafios da leveza: práticas corporais em mutação". In: D. Sant'Anna (org.) Políticas do corpo. São Paulo: Estação Liberdade.

STIGGER, Marco Paulo. 2002. Esporte, lazer e estilo de vida: um estudo etnográfico. Campinas: Autores Associados.

VIEGAS, Marcelo. 2012. "A questão Olímpica". Revista Cemporcento Skate 175: 55 - 59.

V.V.A.A. 2006. "Guia de pistas". Cemporcento Skate. São Paulo: edição especial. 


\title{
Das ruas para os Jogos Olímpicos? Dinâmicas em torno da prática do skate
}

\section{RESUMO}

O presente artigo tem como objetivo apresentar a polêmica em torno da intenção do Comitê Olímpico Internacional (COI) em incluir o skate como uma modalidade olímpica. Para isso o texto irá realizar dois movimentos diferenciados; na primeira parte será feita uma descrição de como o skate surgiu e se desenvolveu como uma prática corporal singular que estabelece uma nova relação com a cidade e seus agentes para além do campo esportivo. Neste sentido ele se apresenta também como uma prática alternativa aos esportes tradicionais que tem atraído a atenção de um universo cada vez mais amplo de pessoas, e com isso trazendo visibilidade e novas possibilidades de diálogo do skate com os mais diversos campos sociais (mercado, mídia, políticas públicas, educação, arte). Na segunda parte a discussão volta-se para as diferentes perspectivas em torno da possível participação do skate nos Jogos Olímpicos como resultado de um processo de maior "esportificação" de sua prática.

PALAVRAS-CHAVE: skate; práticas corporais; esporte e Olimpíadas.

\section{From the streets to the Olympics? Dynamics related to the practice of skate}

\begin{abstract}
This article aims at presenting the controversy around the intention of the International Olympic Committee (IOC) to include skateboarding as an Olympic modality. In order to do so, the text will develop two different lines of thought. In the first section, it will describe how skateboarding emerged and developed as a singular body practice, establishing relationships with urban spaces and its agents that go beyond the field of sportive practices. In this sense, skateboarding is also seen as an alternative to traditional sports. It has attracted the attention of an increasingly broad universe of people, thus bringing visibility and new opportunities of dialogue between skateboard and different social fields (market, media, public policy, education, art).In the second section of the text, the discussion approaches different perspectives about the possible inclusion of skateboarding in the Olympic Games as a result of the process of growing "sportification" of its practice.
\end{abstract}

KEYWORDS: Skateboard; Body practices; Sport and Olympics.

Recebido em: 02/09/2014

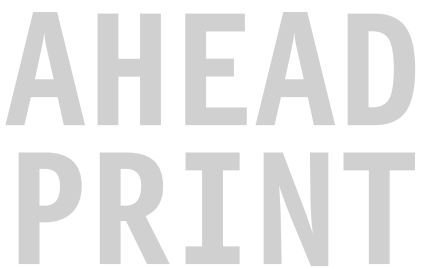

Aprovado em: 19/04/2015 